For resubmission to $35^{\text {th }}$ International Symposium on Combustion February 2014

\title{
High-temperature iso-butene absorption diagnostic for shock tube kinetics using a pulsed quantum cascade laser near $11.3 \mu \mathrm{m}$
}

\author{
R. M. Spearrin*, S. Li, D. F. Davidson, J. B. Jeffries, and R. K. Hanson \\ High Temperature Gasdynamics Laboratory, Department of Mechanical Engineering, \\ Stanford University, Stanford, California 94305, USA \\ *corresponding author: spearrin@stanford.edu
}

\begin{abstract}
A high-bandwidth absorption sensing technique for iso-butene $\left(\mathrm{iC}_{4} \mathrm{H}_{8}\right)$ was developed to measure transient species concentration behind reflected shock waves for combustion kinetics studies. Direct measurements of $\mathrm{iC}_{4} \mathrm{H}_{8}$ were enabled by monitoring absorption in the infrared near $11.3 \mu \mathrm{m}$ using a novel pulsed external-cavity quantum cascade laser (ECQCL) with a repetition rate of $600 \mathrm{kHz}$. Optimal wavelength selection for high-temperature combustion gases was first determined by a spectral survey at $1000 \mathrm{~K}$ near the peak of the absorption band (878 $\mathrm{cm}^{-1}$ to $892 \mathrm{~cm}^{-1}$ ) using the ECQCL. Absorption cross section measurements of $\mathrm{iC}_{4} \mathrm{H}_{8}$ at 881.4 $\mathrm{cm}^{-1}$, the selected high-temperature wavelength, were then conducted from $800 \mathrm{~K}$ to $1800 \mathrm{~K}$ behind reflected shocks to characterize temperature dependence at modest pressures $(4-8 \mathrm{~atm})$. The species-specific technique was subsequently demonstrated by time-resolved (100 kHz) measurements of iso-butene decay during thermal decomposition $(1280-1480 \mathrm{~K})$. First-ever shock tube measurements of $\mathrm{iC}_{4} \mathrm{H}_{8}$ yields from iso-octane pyrolysis $(1070-1300 \mathrm{~K})$ were also produced, with a detection limit of $\sim 100 \mathrm{ppm}$. Experimental results were compared to recent kinetic models to illustrate the potential of this diagnostic for analyzing combustion chemistry.
\end{abstract}

Keywords: laser absorption; iso-butene; fuel pyrolysis; quantum cascade laser; shock tube 


\section{Introduction}

Iso-butene $\left(\mathrm{iC}_{4} \mathrm{H}_{8}\right)$ is a major intermediate species formed by fuel fragmentation processes during pyrolysis and oxidation of large branched alkanes [1]. Iso-butene has been known to slow fuel oxidation by consuming $\mathrm{OH}, \mathrm{O}$ and $\mathrm{H}$ radicals through hydrogen abstraction reactions, and instead of forming reactive fuel radicals, it forms relatively unreactive allene $\left(\mathrm{aC}_{3} \mathrm{H}_{4}\right)$ [2-4]. Thus, the transient concentration of iso-butene during combustion processes provides a sensitive parameter for understanding competing kinetic mechanisms, especially in the context of branched alkane combustion and knock prevention. As such, high-bandwidth species concentration time-history measurements during shock tube kinetics experiments can provide important data for validating and improving chemical kinetic models of various fuel surrogates, perhaps most notably iso-octane. In-situ detection of molecular species including $\mathrm{iC}_{4} \mathrm{H}_{8}$ at time-scales ( $\mu \mathrm{s}$ ) of gas-phase combustion chemistry typically requires optical diagnostics [5]. Here we leverage recent advances in mid-infrared laser technology to develop an absorption sensor for iso-butene, aimed to provide high-bandwidth species concentration measurements for studies of combustion chemistry in shock tubes, with potential application to other combustion systems.

Few reports exist on the infrared absorption spectra of iso-butene, especially at elevated temperatures. Measured room-temperature spectra for iso-butene based on FTIR spectroscopy can be found in the NIST/PNNL database, covering the broad wavelength range of $2.5-20 \mu \mathrm{m}$ [6]. Due to the lack of higher-temperature literature data, these room temperature spectra were used to provide initial guidance for wavelength selection. As depicted in figure 1, iso-butene has a similar infrared absorption spectrum to other alkenes. Like all hydrocarbons, iso-butene has an 
absorption band near $3.4 \mu \mathrm{m}$ due to the $\mathrm{C}-\mathrm{H}$ stretching vibrational mode. Yasunaga et al. recently reported high-temperature $(\mathrm{T}=1000-1800 \mathrm{~K})$ cross-section measurements of isobutene at $3.39 \mu \mathrm{m}$ based on measurements using a $\mathrm{HeNe}$ laser and shock tube [7]. Unfortunately, this vibrational mode is common to all hydrocarbon species, and the individual spectra overlap significantly. Thus, disaggregating information unique to iso-butene during fuel pyrolysis with optical diagnostics near $3.4 \mu \mathrm{m}$ is difficult due to interference from a wide variety of hydrocarbon reaction products [8]. The strongest infrared absorption bands for alkenes are found at longer wavelengths $(10-15 \mu \mathrm{m})$, and can be attributed to the $=\mathrm{C}-\mathrm{H}$ vibrational bending mode, which is further distinguished from other hydrocarbon classes by the presence of the carbon-carbon double bond [9]. Figure 1a illustrates the relative absorption strength and spectral isolation owing to the respective spectral fingerprints of the $=\mathrm{C}-\mathrm{H}$ stretching $(3-3.5$ $\mu \mathrm{m})$ and bending $(10-12 \mu \mathrm{m})$ modes for various C2-C4 alkenes. Fig. 1b shows the spectra of $\mathrm{C}_{4} \mathrm{H}_{8}$ isomers for the bending mode only. The iso-butene absorption band centered near 11.25 $\mu \mathrm{m}\left(890 \mathrm{~cm}^{-1}\right)$ has more than twice the peak absorbance cross-section compared to the band near $3.4 \mu \mathrm{m}\left(2950 \mathrm{~cm}^{-1}\right)$, and exhibits better isolation from potential interfering species.

The present work aims to develop a new diagnostic strategy for high-bandwidth isobutene detection at combustion conditions. The optical method utilizes the absorption band of iso-butene near $11.25 \mu \mathrm{m}$ in order to make sensitive and quantitative measurements of $\mathrm{iC}_{4} \mathrm{H}_{8}$ species concentration behind reflected shock waves at bandwidths sufficient for combustion kinetics $\left(\sim 10^{5} \mathrm{~Hz}\right)$. In the past, spectroscopic access to wavelengths greater than $\sim 10 \mu \mathrm{m}$ with coherent, narrow-band light sources has generally been limited to the spectral emission lines of the $\mathrm{CO}_{2}$ gas laser [10]. An absorption sensor for ethylene near $10.5 \mu \mathrm{m}$ has been developed within our laboratory using a line-tunable continuous-wave $\mathrm{CO}_{2}$ laser for species measurements 
For resubmission to $35^{\text {th }}$ International Symposium on Combustion February 2014

in a shock tube $[11,12]$, but sensing of the vibrational bending modes of other alkenes has been constrained by discretized wavelength output and tuning range limits. Recent progress in quantum cascade lasers (QCLs) has enabled access to mid-infrared wavelengths that were previously unavailable, and here we utilize a newly-developed pulsed external-cavity QCL to exploit the infrared region near $11.3 \mu \mathrm{m}$ for iso-butene detection. Absorption cross-section measurements were made at elevated temperatures to characterize the diagnostic, and the isobutene sensor was demonstrated to produce quantitative species time-histories during iso-butene and iso-octane pyrolysis.

\section{Experimental methods}

\subsection{Shock tube facility}

Mixtures of iso-butene and argon were heated in a shock tube facility described in detail in the literature $[14,15]$. High-temperature $(\mathrm{T}=800-1800 \mathrm{~K})$ iso-butene cross section and concentration time-history measurements were conducted behind reflected shock waves in this high-purity stainless-steel shock tube. The inner diameter of the shock tube, and optical pathlength, is $14.13 \mathrm{~cm}$. Temperatures and pressures behind the reflected shocks were calculated using ideal normal shock relations based on the measured initial conditions and incident shock speed. Incident shock speeds were determined using five piezo-electric pressure transducers spread over the last $1.5 \mathrm{~m}$ of the driven section of the shock tube, which indicate shock arrival times. A linear extrapolation of the velocities derived from the measured arrival times allows calculation of the incident shock speed at the end wall. Temperature uncertainty using this method is typically less than $\pm 1 \%$ [13]. Gas mixtures were prepared manometrically inside a heated mixing tank using research grade argon as the bath gas, homogenized with the various 
fuels by a magnetically driven stirrer for times ranging from 30 minutes to 4 hours. Between reactive experiments, the driven section of the shock tube was pumped down to $\sim 8 \times 10^{-6}$ Torr to remove residual impurities.

\subsection{Optical setup}

Iso-butene absorption measurements are made $2 \mathrm{~cm}$ from the shock tube end wall. Figure 2 provides an illustration of the basic configuration of the absorption diagnostic. A pulsed external-cavity QCL from Block Engineering (Laserscope 712) was utilized as the coherent light source, which is internally collimated $(2 \times 4 \mathrm{~mm}$ beam size $)$ with a beam divergence of less than $5 \mathrm{mrad}$. The ECQCL could be tuned broadly $(7-12 \mu \mathrm{m})$ with a rotating diffraction grating, and has an average output power of approximately $1 \mathrm{~mW}$ at $11.3 \mu \mathrm{m}$. The laser was pulsed at 600 $\mathrm{kHz}$ with a pulse width of $48 \mathrm{~ns}(\sim 3 \%$ duty cycle). Prior to each experiment, the beam was directed to a spectrum analyzer (Bristol 721) to determine the center wavelength and effective line-width. Laser line-width was measured as the cumulative spectral intensity distribution at an acquisition rate of $\sim 0.5 \mathrm{~Hz}$. Due to the long integration time of the spectrum analyzer, a singlepulse line-width could not be resolved, but rather an aggregate line-width averaged over many pulses resulting from pulse-to-pulse variation and intra-pulse chirping. Typical effective linewidths were measured to be approximately $0.5 \mathrm{~cm}^{-1}$, corresponding to the characteristic mode spacing of the ECQCL near $11 \mu \mathrm{m}$. Utilizing the spectrum analyzer, the laser could be carefully tuned such that only a single lasing mode was active and line-widths of less than $0.2 \mathrm{~cm}^{-1}$ could be achieved with lower pulse-to-pulse power variation $(\sim 2 \%)$. The beam was pitched perpendicular to the shock tube through barium-fluoride windows, and the transmitted light was focused by a $50 \mathrm{~mm}$ f.l. zinc-selenide plano-convex lens onto a Vigo photovoltaic detector 
(PVM-2TE-10.6) with a 3 ns time constant. The detector pre-amplifier low-pass filtered the pulsed light at $10 \mathrm{MHz}$, and data was sampled at the same rate. Due to the high pulse rate, short pulse width of the laser, and detector time resolution, the detector background, which typically included infrared thermal emission at combustion conditions, could be monitored between pulses and subtracted from the detector signal during the adjacent laser pulses. This inter-pulse emission-subtraction method eliminates the need for separate emission measurements that can complicate data post-processing and add measurement uncertainty to continuous-wave laser absorption methods.

\section{Cross section measurements}

Isobutene absorption measurements initially targeted the room-temperature peak of the Q-branch of the vibrational bending mode near $890 \mathrm{~cm}^{-1}(11.24 \mu \mathrm{m})$ [6]. The measured quantities of incident $\left(I_{0}\right)$ and transmitted $\left(I_{t}\right)$ light were related to thermodynamic properties by the Beer-Lambert law:

$$
\alpha_{v}=-\ln \left(\frac{I_{t}}{I_{0}}\right)_{v}=\sigma_{v} n_{a b s} L
$$

where $\alpha_{v}$ is the spectral absorbance at frequency $v\left[\mathrm{~cm}^{-1}\right]$, which is defined as the product of the absorption cross section, $\sigma_{v}\left[\mathrm{~m}^{2} / \mathrm{mol}\right]$, number density of the absorbing species, $n_{a b s}\left[\mathrm{~mol} / \mathrm{m}^{3}\right]$, and path-length, $L[\mathrm{~m}]$. The light intensity terms $\left(I_{0}\right.$ and $\left.I_{t}\right)$ are defined here by a numerical integration of each laser pulse, effectively a summation of photons which was observed to vary much less than peak values pulse-to-pulse. The maximum measurement bandwidth post- 
integration is equivalent to the pulse frequency $(\sim 600 \mathrm{kHz})$, which was filtered further to 100 $\mathrm{kHz}$ to smooth pulse-to-pulse power fluctuations for most experiments. Figure 3 shows a representative pressure and iso-butene absorbance time-history for a non-reactive shock tube experiment of $\mathrm{iC}_{4} \mathrm{H}_{8}$ and argon mixture using this method. The absorption cross section at a given laser frequency was determined by equation 1 with knowledge of the temperature and pressure in each shock region.

Cross section values for iso-butene near $890 \mathrm{~cm}^{-1}$, though superior in magnitude at room temperature, were found to be undesirably low $\left(<4 \mathrm{~m}^{2} / \mathrm{mol}\right)$ at elevated temperatures $(>1000$ $\mathrm{K})$, leading to an investigation of the surrounding wavelength domain for stronger absorption. Non-reactive shock tube experiments were then repeated at approximately the same thermodynamic conditions $\left(1 \% \mathrm{iC}_{4} \mathrm{H}_{8} / \mathrm{Ar}, \mathrm{T}_{5} \sim 1000 \mathrm{~K}\right)$ over the wavenumber range from 878 $\mathrm{cm}^{-1}$ to $892 \mathrm{~cm}^{-1}$, within which the ECQCL was step-tuned to available individual lasing modes with effective line-widths of $0.15-0.3 \mathrm{~cm}^{-1}$, spaced every $0.5-1 \mathrm{~cm}^{-1}$. Figure 4 depicts the relative cross sections as measured over this domain, normalized by the peak cross section for each temperature $(300 \mathrm{~K}, 600 \mathrm{~K}, 1000 \mathrm{~K})$, related to the three regions of the shock tube experiment (pre-shock, post-incident shock, and post-reflected shock). As evidenced, the rovibrational bands of the Q-branch broaden at elevated temperatures, as would be expected, and the peak cross section shifts toward lower wavenumbers (i.e., higher wavelengths) by approximately $1 \mathrm{~cm}^{-1}$ per $100 \mathrm{~K}$. Given the primary target temperature range for reactive isobutene experiments of $1000-1500 \mathrm{~K}$, we chose a lasing mode near $881.4 \mathrm{~cm}^{-1}$.

Quantitative cross section measurements near $881.4 \mathrm{~cm}^{-1}$ of iso-butene and potential interference absorption by ethylene $\left(\mathrm{C}_{2} \mathrm{H}_{4}\right)$ and propene $\left(\mathrm{C}_{3} \mathrm{H}_{6}\right)$ were then made at various temperatures $(800-1800 \mathrm{~K})$ relevant for combustion kinetics studies as these species are often 
present with other alkenes as intermediates of branched alkane decomposition [16,17]. Figure 5 shows the cross section data for the three species, each measured at approximately $1 \%$ mole fraction dilute in argon over a range of intermediate pressures $(\mathrm{P}=3.5-7.5 \mathrm{~atm})$. The isobutene cross section data at $881.4 \mathrm{~cm}^{-1}$ can be fit with an exponential decay function to capture temperature dependence:

$$
\sigma(T) \mathrm{m}^{2} / \mathrm{mol}=(16.91) \exp (-(0.00124) T)+1.02
$$

Cross sections of $\mathrm{C}_{2} \mathrm{H}_{4}$ and $\mathrm{C}_{3} \mathrm{H}_{6}$ have weak temperature dependence and are determined at intermediate temperatures by simple linear interpolation. While pressure dependence was observed to be less than measurement uncertainty for these experiments, caution should be taken extending these cross section data to a broader range of conditions.

\section{Iso-butene decomposition}

Iso-butene cross section measurements at temperatures greater than $1250 \mathrm{~K}$ revealed considerable decay in absorbance behind the reflected shock wave resulting from thermal decomposition reactions. Figure 6 illustrates an example of this decay over a period of near constant-pressure at $1477 \mathrm{~K}$. Cross section values at these high temperatures were determined by extrapolating absorbance to the arrival time of the reflected shock $(t=0)$. Near the end of the test time ( $\sim 2 \mathrm{~ms})$, absorbance approaches a non-zero asymptote, indicating interference from intermediates of iso-butene pyrolysis. This asymptotic value provides an estimate of the maximum cumulative interference given that the intermediates are increasing as iso-butene decays. To correct for this interference, a second cross-section measurement was made for the 
same condition at $891.1 \mathrm{~cm}^{-1}$. By measuring iso-butene at two wavelengths, and assuming interference is wavelength-independent over this domain, the two-color measurement scheme allows for solution of the two unknown parameters of iso-butene absorbance and interfering absorbance [18]. After subtracting the interference, iso-butene absorbance was converted to mole fraction based on known cross section values. Figure 7 demonstrates this measurement technique to resolve iso-butene species time-histories for decomposition over a range of temperatures $(1280-1480 \mathrm{~K})$. The data exhibit a signal-to-noise ratio (SNR) of approximately 40 at a concentration of $6000 \mathrm{ppm}$, implying a detection limit of $\sim 150 \mathrm{ppm}$ for typical conditions $(\mathrm{T} \sim 1350 \mathrm{~K}, \mathrm{P} \sim 5.5 \mathrm{~atm})$ at a bandwidth of $100 \mathrm{kHz}$. The iso-butene concentration time-history measurements for decomposition are compared to kinetic simulations at the same conditions using the JetSurf 2.0 mechanism [19]. The experimental data suggest that the decomposition rate of iso-butene is generally faster than predicted by this mechanism. Due to relative uncertainties in the mechanism, this discrepancy is likely caused by error in the rate constants of reactions involving $\mathrm{iC}_{4} \mathrm{H}_{7}$ (2-methylpropen-3-yl), which is an important intermediate radical for iso-butene decomposition.

\section{Iso-octane pyrolysis}

In addition to iso-butene decay, we also utilized this new diagnostic to demonstrate timeresolved measurements of $\mathrm{iC}_{4} \mathrm{H}_{8}$ formation during iso-octane pyrolysis. Iso-octane is an important component of automotive gasoline, often used in large proportions to increase the knock resistance of the fuel [20]. Figure 8 shows a simulation of iso-octane pyrolysis at $1250 \mathrm{~K}$ using the kinetic mechanism from Mehl et al. at Lawrence Livermore National Laboratory (LLNL) [1]. The simulated mole fraction time-histories as plotted highlight the major 
For resubmission to $35^{\text {th }}$ International Symposium on Combustion February 2014

intermediate species which are formed within the first millisecond of $\mathrm{iC}_{8} \mathrm{H}_{18}$ pyrolysis. As can be observed, iso-butene is predicted to form the fastest amongst the intermediates, and maintains the highest yield of all intermediates for nearly $1 \mathrm{~ms}$. The second most abundant intermediate is propene, while other alkenes such as ethylene exhibit much lower yields by a factor of 5 or more compared to iso-butene. The dominant formation of $\mathrm{iC}_{4} \mathrm{H}_{8}$ points to the potential of our new diagnostic to provide a sensitive measurement of kinetics.

Figure 9 depicts measured, time-resolved iso-butene yields from iso-octane pyrolysis at a range of temperatures from $1070-1300 \mathrm{~K}$. Measurements are compared to kinetic simulations using the LLNL model. Interference from other intermediate species such as propene was subtracted using the method described in section 4. At these temperatures and pressures $(\mathrm{P} \sim 5.5$ - $6.5 \mathrm{~atm})$, the detection limit is slightly lower ( 100 ppm) compared to the iso-butene decomposition studies. The measured rates of $\mathrm{iC}_{4} \mathrm{H}_{8}$ formation at early times show very good agreement with the kinetic model across all temperatures, while the measured yields at longer times are higher (by up to 30\%) with increasing disagreement at higher temperatures. Further studies are needed for quantitative kinetic analysis.

\section{Uncertainties and potential improvements}

Given the first-time nature of these measurements and general immaturity of highbandwidth optical equipment at such long wavelengths $(>11 \mu \mathrm{m})$, the laboratory work conducted here revealed a number of sources of uncertainty and potential improvements with regard to the laser source, detector, and optical setup that can be refined in future experiments. Since completion of this initial work, a collaborative effort was commenced with the laser manufacturer (Block Engineering) to improve the light source for high-bandwidth, fixed- 
wavelength studies, and to better optimize the optical configuration and pulse settings. Specifically, the laser pulse-to-pulse power variation $(\sim 1 \%)$, which translated to significant noise in the measured absorbance $(2-10 \%)$, is expected to be improved with a higher maximum pulse rate. The wavelength resolution of the laser, concerning the available lasing modes, can also be increased, yielding greater spectroscopic flexibility for optimal wavelength selection. The photovoltaic detector used here, optimized for a $\mathrm{CO}_{2}$ laser at $10.6 \mu \mathrm{m}$, manifested substantially reduced sensitivity and linearity at $11.3 \mu \mathrm{m}$. A systematic measurement uncertainty $(\sim 10 \%)$ was estimated to be attributable to the detector non-linearity. A new detector, which is optimized for longer wavelengths, may improve sensitivity and reduce noise and non-linearity error. Additionally, to accurately resolve higher pulse rates, and shorter pulse widths, a detector with a higher bandwidth is recommended. Spectroscopically, some potentially interfering species, such as allene $\left(\mathrm{aC}_{3} \mathrm{H}_{4}\right)$ were not measured. Uncertainty in the interference subtraction method, as utilized for the present sensor, would result from a strong wavelength dependence of allene or other species near $11.3 \mu \mathrm{m}$. While the wavelength dependence of propene and ethylene were found to be very weak, future validation measurements of all potential interferers would mitigate this source of uncertainty.

\section{Conclusions}

The present work introduces a novel absorption diagnostic to measure iso-butene concentrations in high-temperature shock tube kinetics studies. A pulsed external-cavity quantum cascade laser was utilized to probe the infrared absorption of $\mathrm{iC}_{4} \mathrm{H}_{8}$ near $11.3 \mu \mathrm{m}$. High-temperature absorption measurements near the Q-branch peak of the $=\mathrm{C}-\mathrm{H}$ vibrational

bending mode $\left(\sim 890 \mathrm{~cm}^{-1}\right)$ were conducted in shock-heated gas mixtures of iso-butene in argon 
For resubmission to $35^{\text {th }}$ International Symposium on Combustion February 2014

to determine optimal wavelength selection for combustion temperatures. The peak shift was determined to be approximately $1 \mathrm{~cm}^{-1}$ per $100 \mathrm{~K}$ toward longer wavelengths (lower wavenumbers). Cross section measurements near $881.4 \mathrm{~cm}^{-1}$ were carried out over a range of combustion temperatures $(800-1800 \mathrm{~K})$ for iso-butene $(1 \%)$ in argon at pressures of $4-8$ atm, and an exponential function was fit to the cross section data to characterize cross section temperature dependence over this range. Absorption cross sections were also measured for propene and ethylene at the same wavelength to account for potential interference in combustion gases. Species time-histories of iso-butene pyrolysis were measured in the temperature domain of $1250-1500 \mathrm{~K}$, exhibiting the ability to provide a direct measurement of isobutene decay at a bandwidth of $\sim 100 \mathrm{KHz}$. Iso-butene formation time-histories from iso-octane pyrolysis were also measured. To the authors' knowledge, these measurements represent the first hightemperature iso-butene data probing the strong infrared vibrational band near $11.3 \mu \mathrm{m}$, as well as the first time-resolved measurements of iso-butene yields from iso-octane pyrolysis in a shock tube. More broadly, this work highlights the ability of our new diagnostic method to directly measure a species important to combustion chemistry $\left(\mathrm{iC}_{4} \mathrm{H}_{8}\right)$ at high bandwidths and high temperatures, providing a diagnostic framework to enable a number of future studies of combustion kinetics that were previously not feasible.

\section{Acknowledgements}

The authors would like to thank Block Engineering, Inc. and Pembroke Instruments for arranging the loan of the laser source as well as technical support. The research efforts were supported by the Air Force Office of Scientific Research (AFOSR) through the Basic Research Initiative (BRI) program (FA9550-12-1-0472) with Dr. Chiping Li as program manager. Chemical kinetics analysis in this study was supported by the Combustion Energy Frontier 
Research Center funded by the U. S. Department of Energy, Office of Basic Energy Sciences under Award Number DE-SC0001198.

\section{References}

1. M. Mehl, W. J. Pitz, C. K. Westbrook, and H. J. Curran, Proc. Combust. Inst. 33 (2011) 193-200.

2. K. Brezinsky and F. L. Dryer, Combust. Sci. Technol. 45 (1986) 225-232.

3. H. J. Curran, M. P. Dunphy, J. M. Simmie, C. K. Westbrook, and W. J. Pitz, Symp. Combust. 24 (1992) 769-776.

4. N. Liu, S. Mani Sarathy, C. K. Westbrook, and F. N. Egolfopoulos, Proc. Combust. Inst. 34 (2013) 903-910.

5. R. K. Hanson, Proc. Combust. Inst. 33 (2011) 1-40.

6. S. W. Sharpe, T. J. Johnson, R. L. Sams, P. M. Chu, G. C. Rhoderick, and P. A. Johnson, Appl. Spectrosc. 58 (2004) 1452-1461.

7. K. Yasunaga, Y. Kuraguchi, R. Ikeuchi, H. Masaoka, O. Takahashi, T. Koike, and Y. Hidaka, Proc. Combust. Inst. 32 (2009) 453-460.

8. A. E. Klingbeil, J. B. Jeffries, and R. K. Hanson, J. Quant. Spectrosc. Radiat. Transf. 107 (2007) 407-42.

9. G. Herzberg, Molecular Spectra and Molecular Structure: Infrared and Raman of Polyatomic Molecules, Krieger Pub Co, 1991, p. 650.

10. W. J. Witteman, The $\mathrm{CO}_{2}$ laser, Springer-Verlag Opt. Sci. Vol. 53, 1987, p. 53.

11. G. L. Pilla, D. F. Davidson, and R. K. Hanson, Proc. Combust. Inst. 33 (2011) 333-340.

12. W. Ren, D. F. Davidson, and R. K. Hanson, Int. J. Chem. Kinet. 44 (2012) 423-432.

13. I. Stranic, D. F. Davidson, and R. K. Hanson, Chem. Phys. Lett. 584 (2013) 18-23.

14. M. A. Oehlschlaeger, D. F. Davidson, and R. K. Hanson, J. Phys. Chem. A 108 (2004) 4247-4253. 
15. I. Stranic, D. P. Chase, J. T. Harmon, S. Yang, D. F. Davidson, and R. K. Hanson, Combust. Flame 159 (2012) 516-527.

16. C. K. Westbrook, F. L. Dryer, and K. P. Schug, Symp. Combust. 19 (1982) 153-166.

17. C. K. Westbrook and W. J. Pitz, Combust. Sci. Technol. 37 (1984) 117-152.

18. S. H. Pyun, J. Cho, D. F. Davidson, and R. K. Hanson, Meas. Sci. Technol. 22 (2011) 025303.

19. H. Wang, E. Dames, B. Sirjean, D. Sheen, R. Tangko, A. Violi, J. Lai, F. Egolfopoulos, D. Davidson, R. Hanson, C. Bowman, C. Law, W. Tsang, N. Cernansky, D. Miller, and R. Lindstedt, JetSurF version 2.0 (2010).

20. W. Dabelstein, A. Reglitzky, A. Schütze, and K. Reders, Ullmann's Encyclopedia of Industrial Chemistry: Automotive Fuels, Wiley-VCH Verlag GmbH \& Co. KGaA, 2000. 
Figure Captions:

(a)

(b)

Fig. 1. Infrared absorption cross-sections for (a) various C2-C4 alkenes and (b) isomers of butene; $\mathrm{T}=296 \mathrm{~K}[6]$.

Fig. 2. Schematic of iso-butene detection using the pulsed ECQCL.

Fig. 3. Example shock tube time-history of measured pressure and iso-butene absorbance near $881 \mathrm{~cm}^{-1}$. Time zero indicates the passage of the reflected shock wave at the optical measurement location $2 \mathrm{~cm}$ from end wall.

Fig. 4. Measurements of iso-butene cross-sections near $11.3 \mu \mathrm{m}$ at $\mathrm{T}=300 \mathrm{~K}$ (square), $600 \mathrm{~K}$ (circle), and $1000 \mathrm{~K}$ (triangle) in argon, normalized by the maximum cross-section of each respective temperature.

Fig. 5. Iso-butene cross section measurements at $881.4 \mathrm{~cm}^{-1}$ for temperatures relevant to combustion kinetics $(\mathrm{T}=800-1800 \mathrm{~K})$; cross sections for potential interfering species (propene and ethylene) also shown; $\mathrm{P}=3.5-7.5 \mathrm{~atm}$, argon bath gas.

Fig. 6. Measured iso-butene absorbance and pressure time-histories during iso-butene decomposition. Reflected shock conditions: $1477 \mathrm{~K}, 5.5 \mathrm{~atm}, 1 \% \mathrm{iC}_{4} \mathrm{H}_{8} / \mathrm{Ar}$.

Fig. 7. Iso-butene decomposition time-histories with comparisons to kinetic simulations (JetSurf 2.0); $\mathrm{T}=1279-1477 \mathrm{~K}, \mathrm{P}=5-6 \mathrm{~atm}$, initial mixtures $1 \% \mathrm{iC}_{4} \mathrm{H}_{8} / \mathrm{Ar}$. 
For resubmission to $35^{\text {th }}$ International Symposium on Combustion February 2014

Fig. 8. Simulation of iso-octane pyrolysis at $1250 \mathrm{~K}$ showing yields of top intermediates; $\mathrm{P}=$ $5.5 \mathrm{~atm}, 1 \% \mathrm{iC}_{8} \mathrm{H}_{18} / \mathrm{Ar}$ mixture.

Fig. 9. Iso-octane pyrolysis time histories showing iso-butene yields and comparison to kinetic simulations (LLNL); $\mathrm{T}=1073-1301 \mathrm{~K}, \mathrm{P}=5-6.5 \mathrm{~atm}, 1 \% \mathrm{iC}_{8} \mathrm{H}_{18} /$ Ar mixture. 
For resubmission to $35^{\text {th }}$ International Symposium on Combustion February 2014

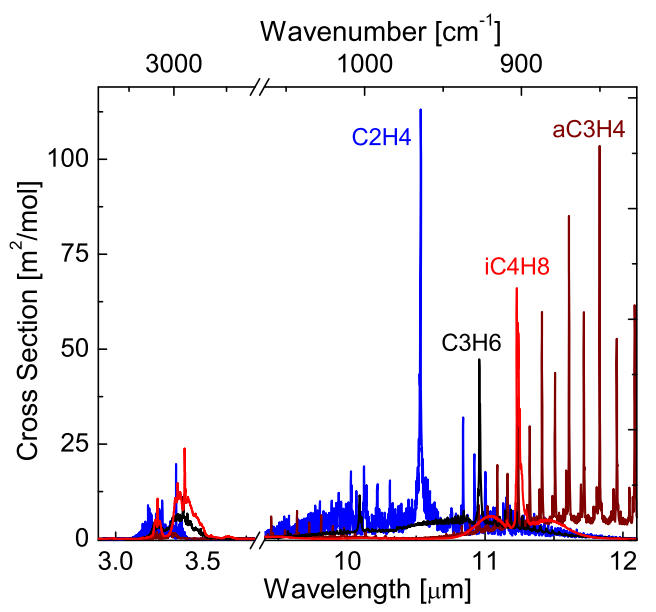

(a)

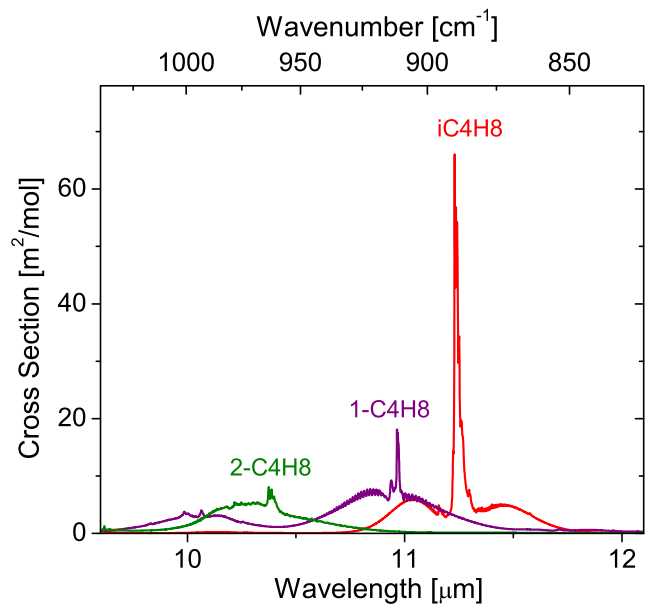

(b)

Fig. 1. Infrared absorption cross-sections for (a) various $\mathrm{C} 2-\mathrm{C} 4$ alkenes and (b) isomers of butene; $\mathrm{T}=296 \mathrm{~K}[6]$.

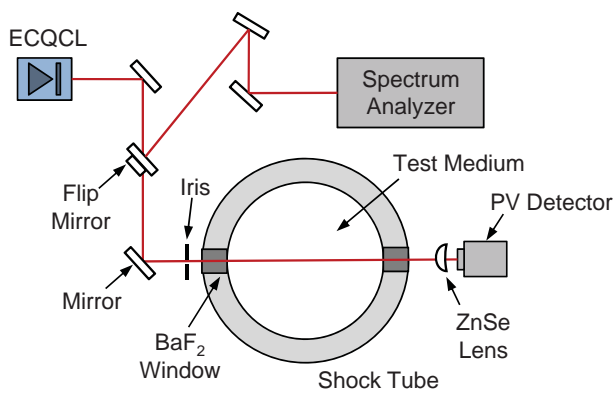

Fig. 2. Schematic of iso-butene detection using the pulsed ECQCL.

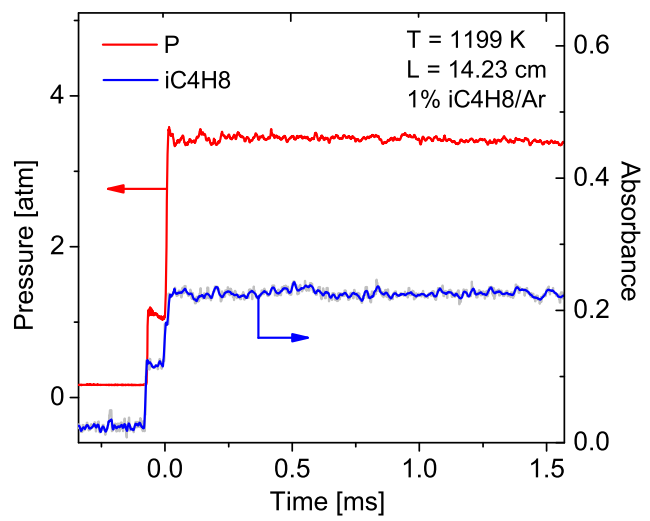

Fig. 3. Example shock tube time-history of measured pressure and iso-butene absorbance near $881 \mathrm{~cm}^{-1}$. Time zero indicates the passage of the reflected shock wave at the optical measurement location $2 \mathrm{~cm}$ from end wall. 
For resubmission to $35^{\text {th }}$ International Symposium on Combustion February 2014

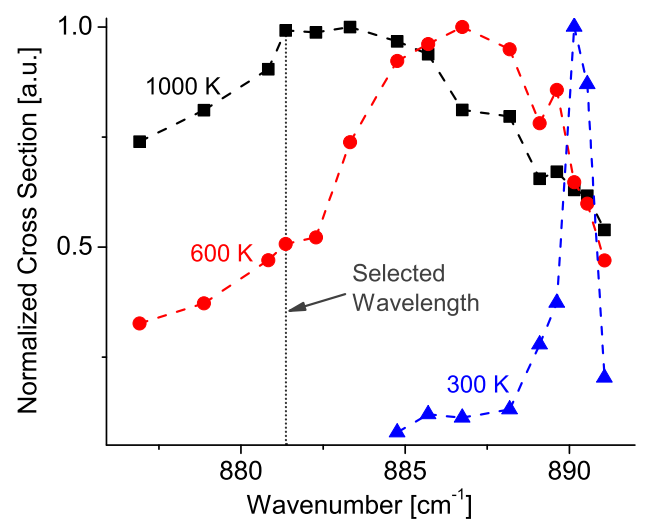

Fig. 4. Measurements of iso-butene cross-sections near $11.3 \mu \mathrm{m}$ at $\mathrm{T}=300 \mathrm{~K}$ (square), $600 \mathrm{~K}$ (circle), and $1000 \mathrm{~K}$ (triangle) in argon, normalized by the maximum cross-section of each respective temperature.

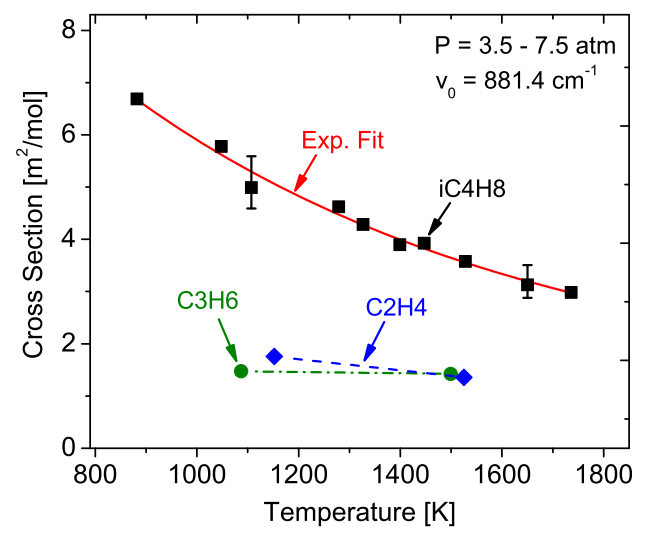

Fig. 5. Iso-butene cross section measurements at $881.4 \mathrm{~cm}^{-1}$ for temperatures relevant to combustion kinetics $(\mathrm{T}=800-1800 \mathrm{~K})$; cross sections for potential interfering species (propene and ethylene) also shown; $\mathrm{P}=3.5-7.5 \mathrm{~atm}$, argon bath gas. 
For resubmission to $35^{\text {th }}$ International Symposium on Combustion February 2014

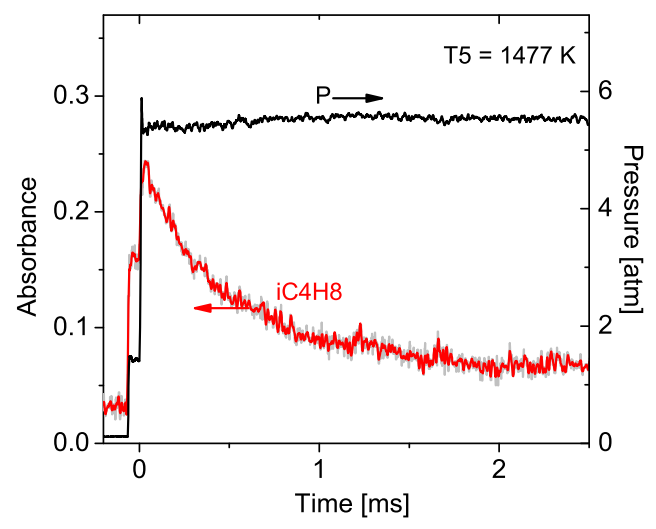

Fig. 6. Measured iso-butene absorbance and pressure time-histories during iso-butene decomposition. Reflected shock conditions: $1477 \mathrm{~K}, 5.5 \mathrm{~atm}, 1 \% \mathrm{iC}_{4} \mathrm{H}_{8} / \mathrm{Ar}$.

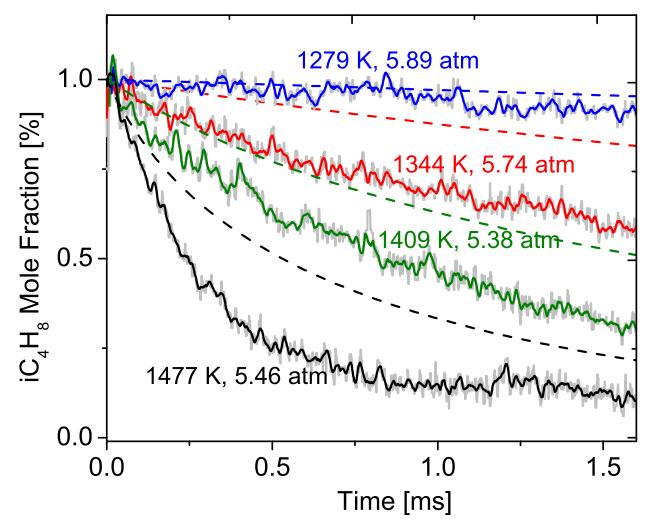

Fig. 7. Iso-butene decomposition time-histories with comparisons to kinetic simulations (JetSurf 2.0); $\mathrm{T}=1279-1477 \mathrm{~K}, \mathrm{P}=5-6$ atm, initial mixtures $1 \% \mathrm{iC}_{4} \mathrm{H}_{8} / \mathrm{Ar}$.

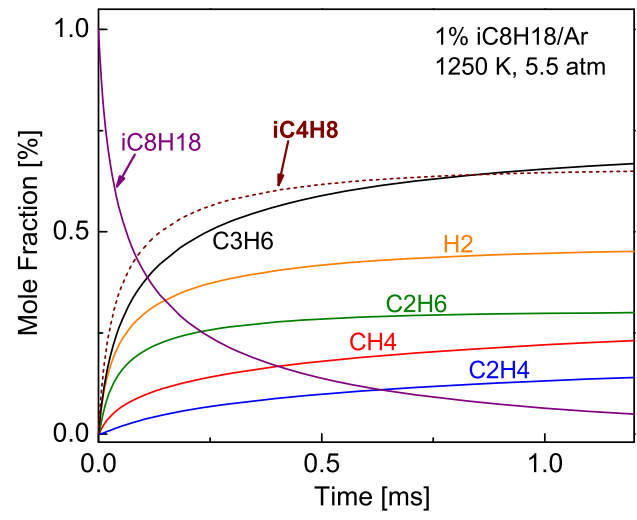

Fig. 8. Simulation of iso-octane pyrolysis at $1250 \mathrm{~K}$ showing yields of top intermediates; $\mathrm{P}=$ $5.5 \mathrm{~atm}, 1 \% \mathrm{iC}_{8} \mathrm{H}_{18} /$ Ar mixture. 
For resubmission to $35^{\text {th }}$ International Symposium on Combustion February 2014

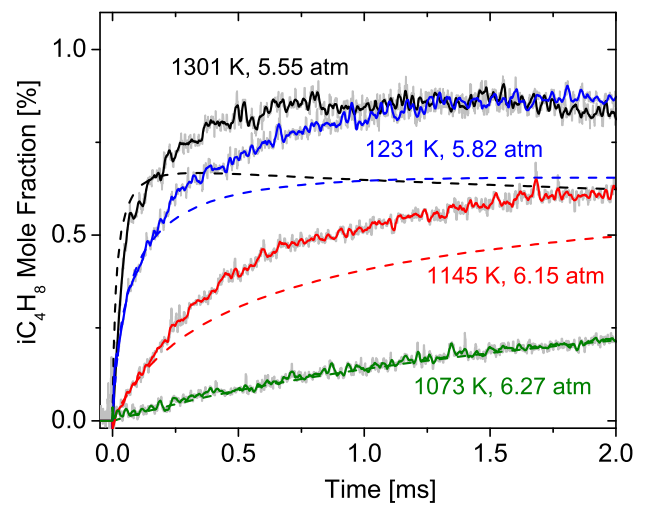

Fig. 9. Iso-octane pyrolysis time histories showing iso-butene yields and comparison to kinetic simulations (LLNL); $\mathrm{T}=1073-1301 \mathrm{~K}, \mathrm{P}=5-6.5 \mathrm{~atm}, 1 \% \mathrm{iC}_{8} \mathrm{H}_{18} / \mathrm{Ar}$ mixture. 


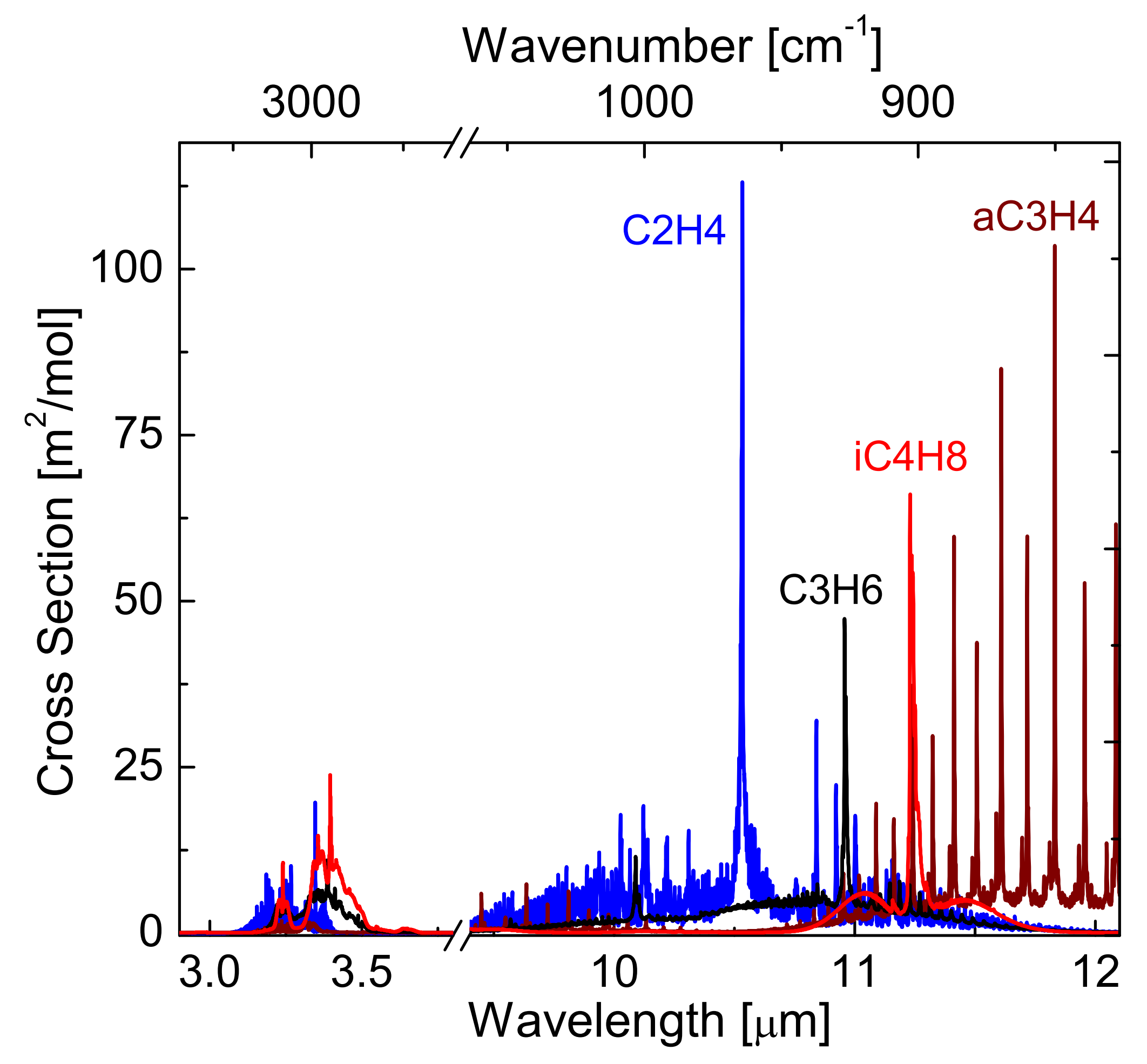

Figure1a 


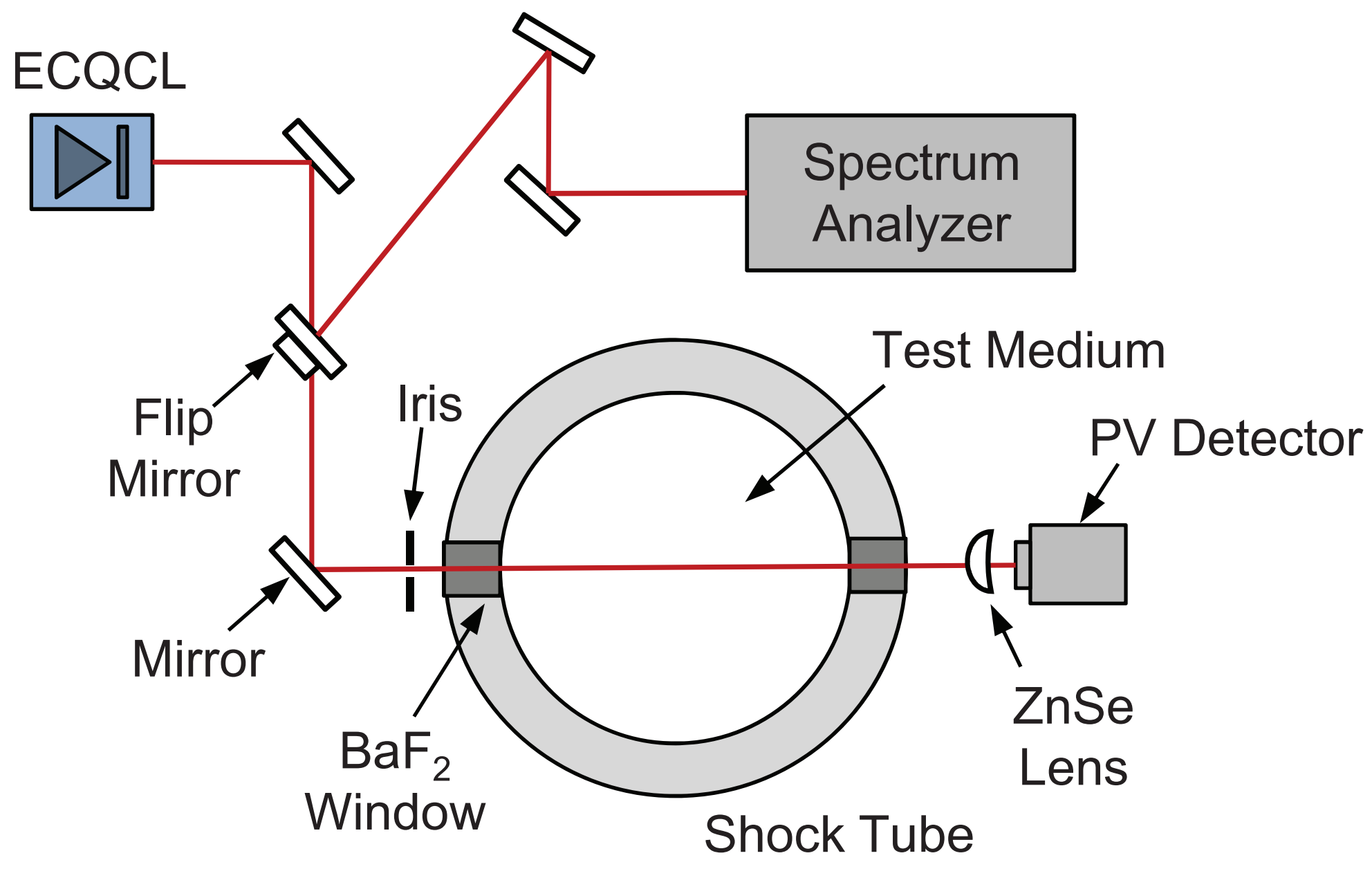

Flip Iris

Mirror

Spectrum

Analyzer

Test Medium

PV Detector

$\mathrm{ZnSe}$

Lens

Shock Tube 


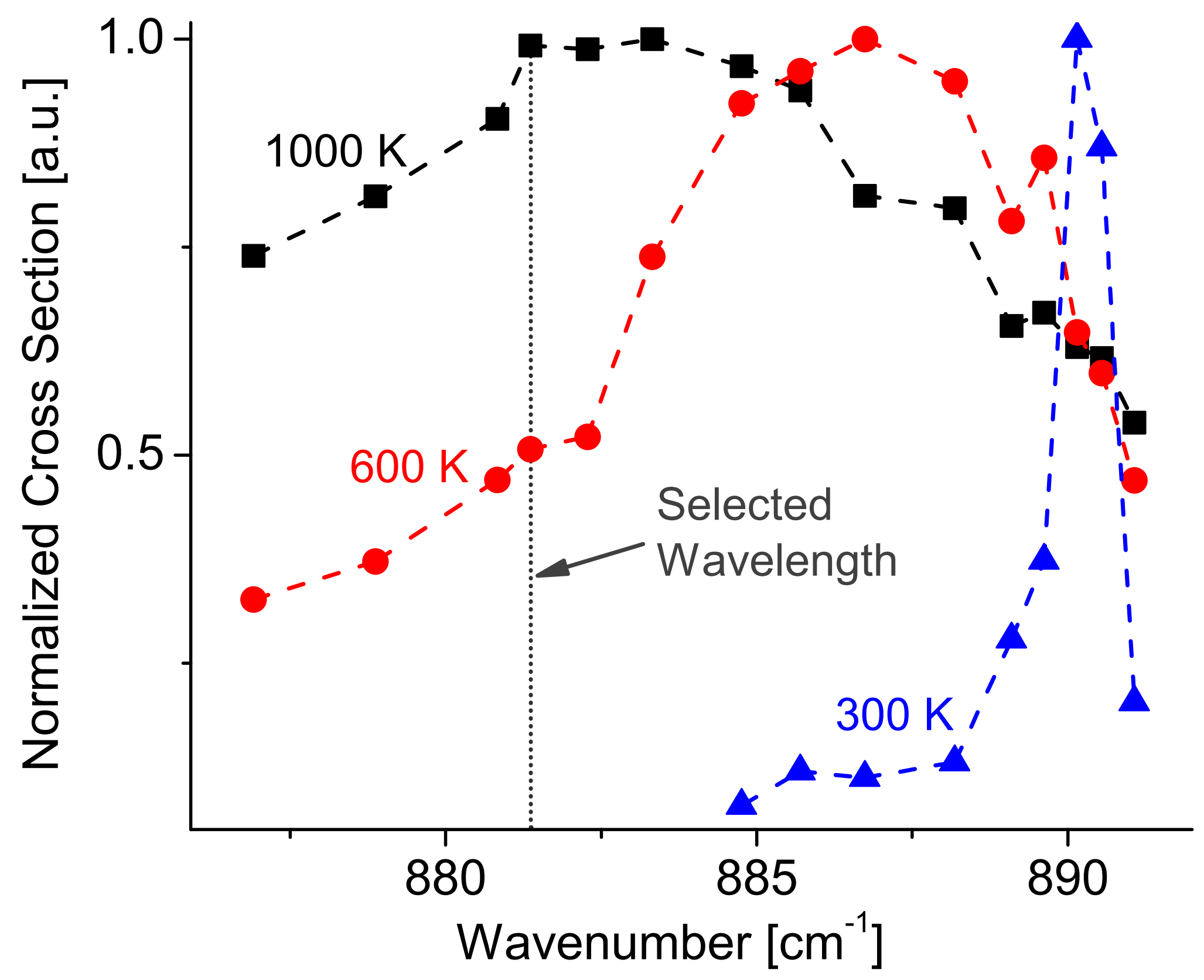


Figure5
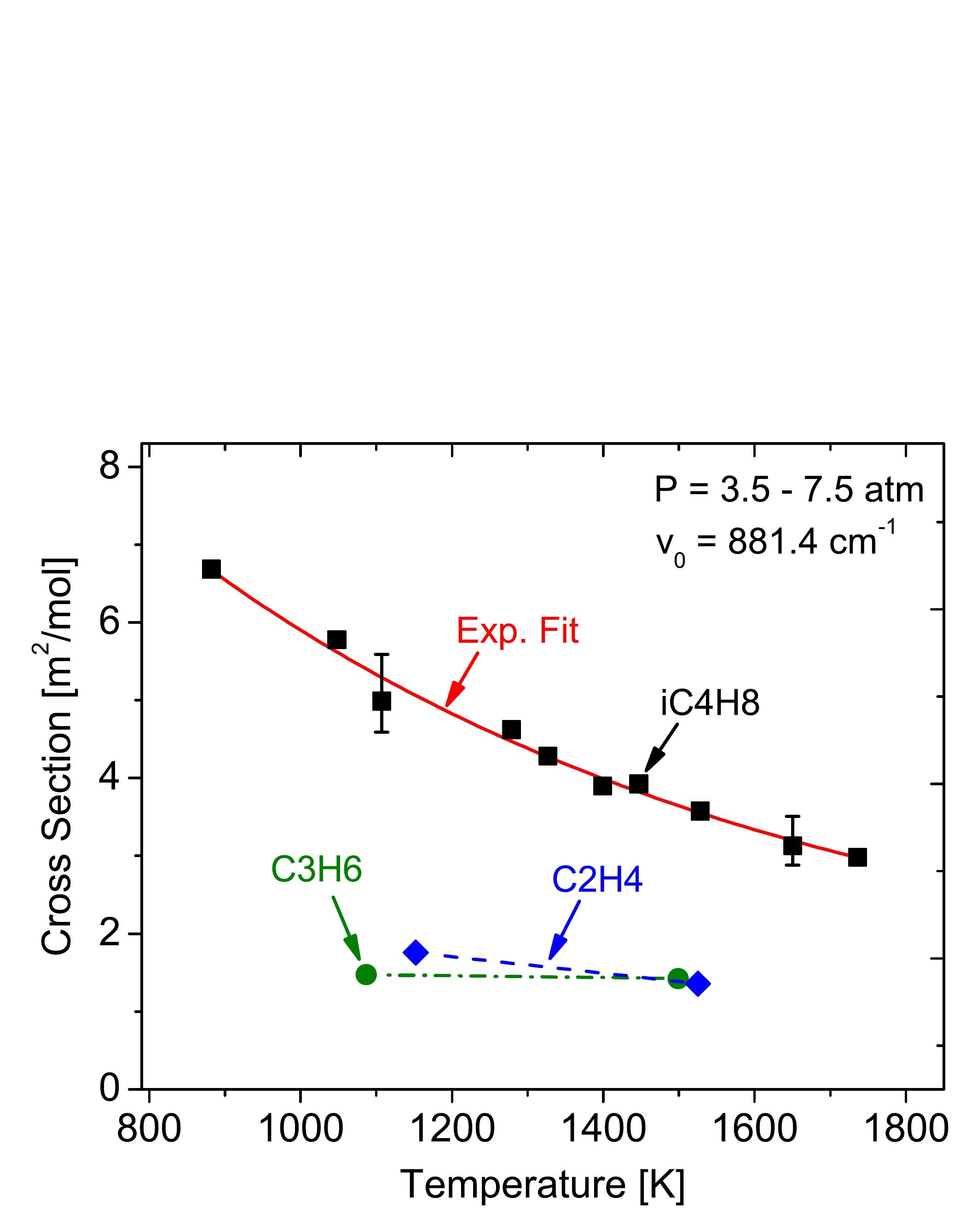

(⿸丆口
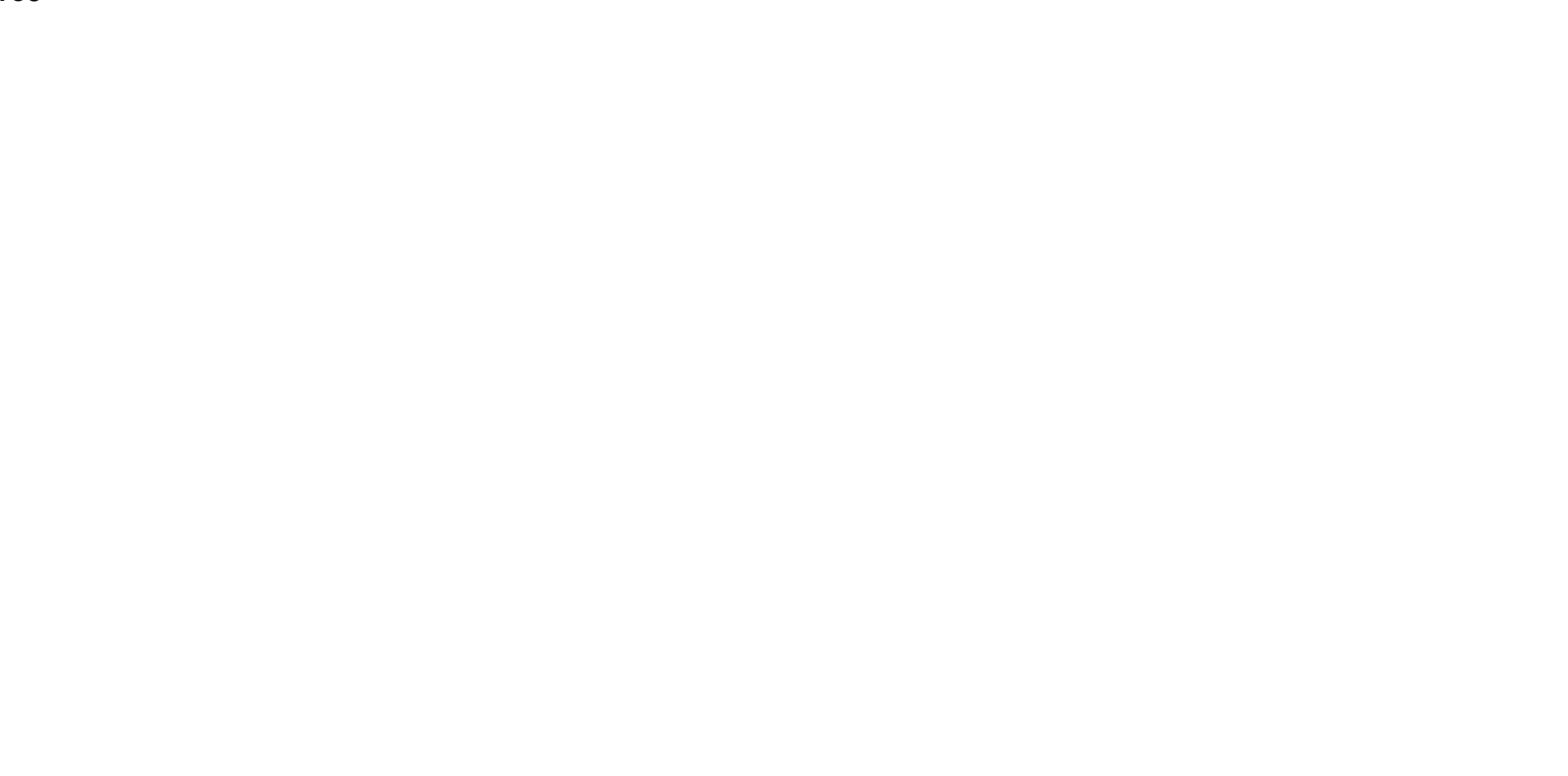

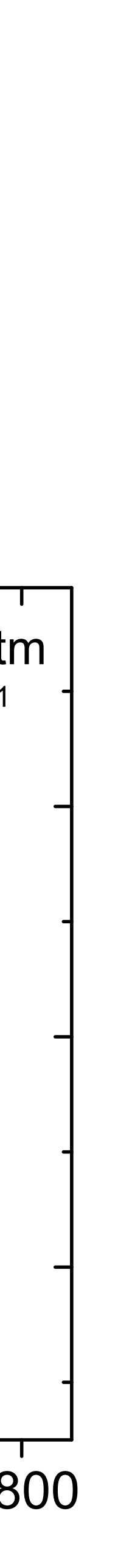




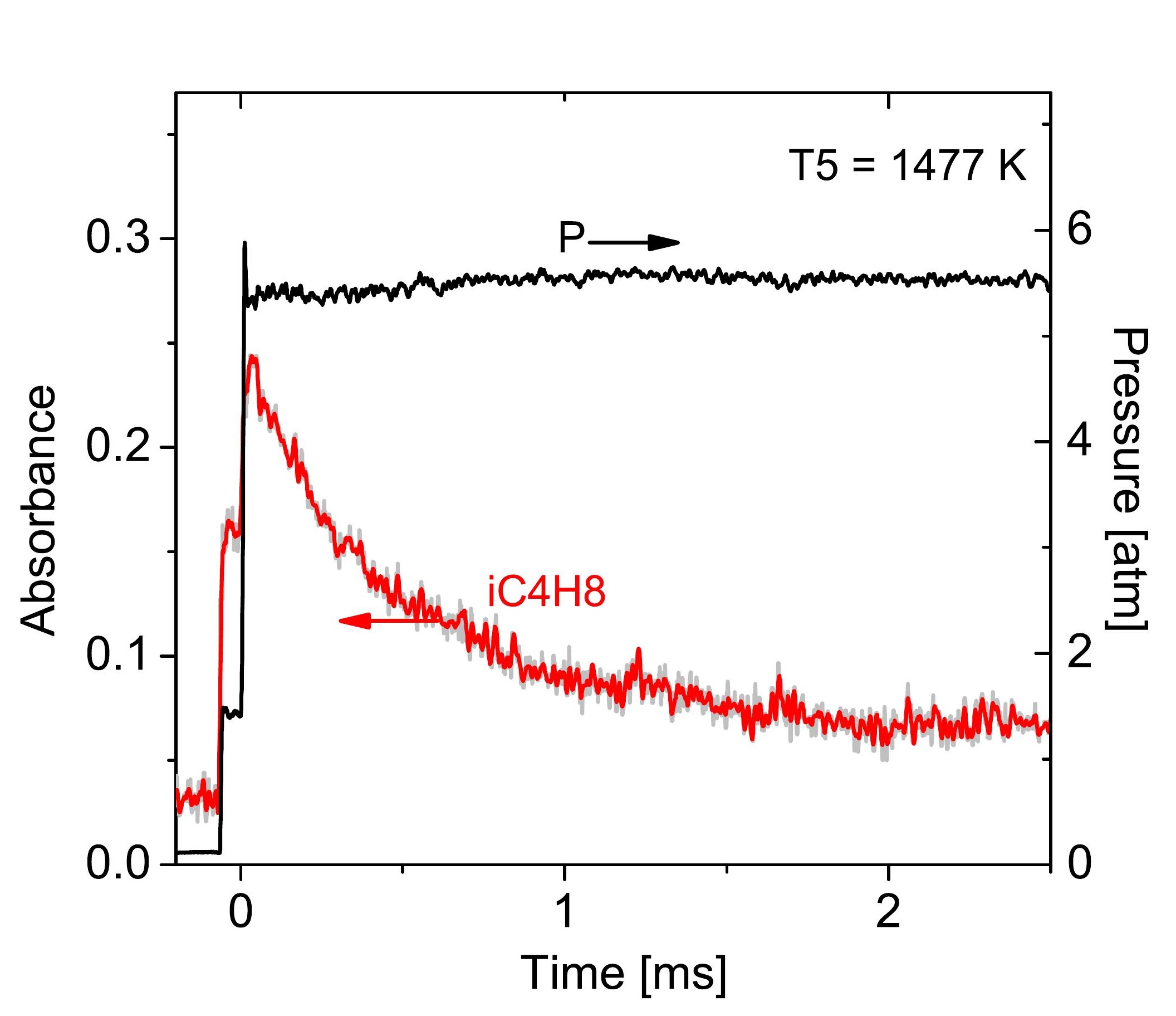

Figure6

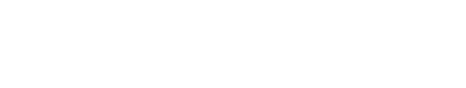

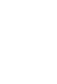
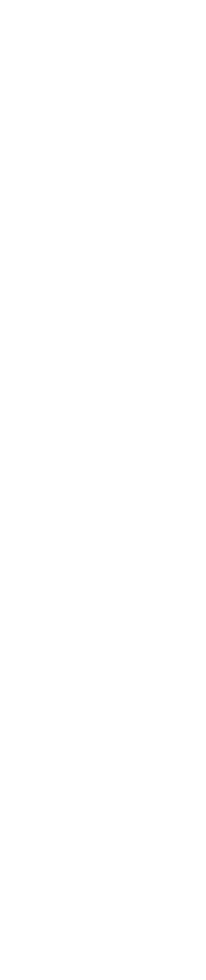

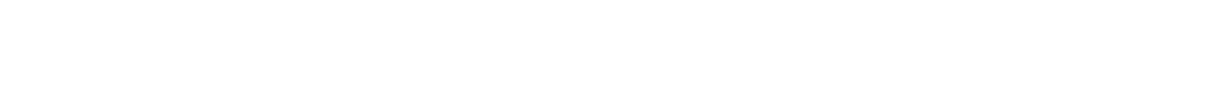

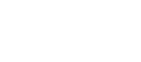

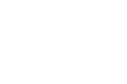

(1)

(1)

(1)

(1)
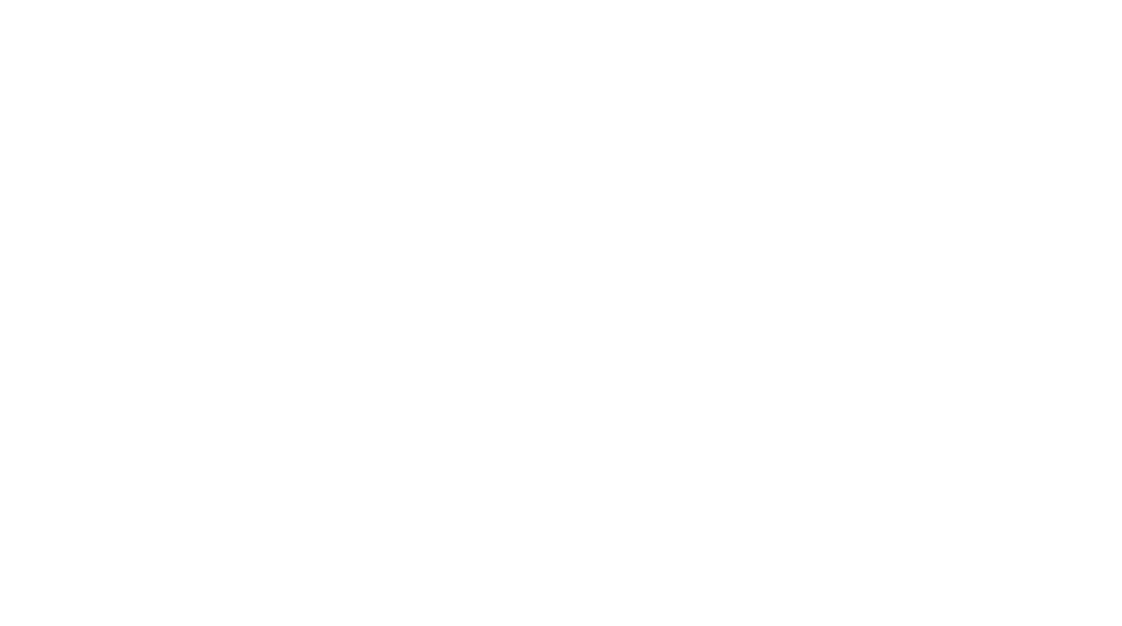


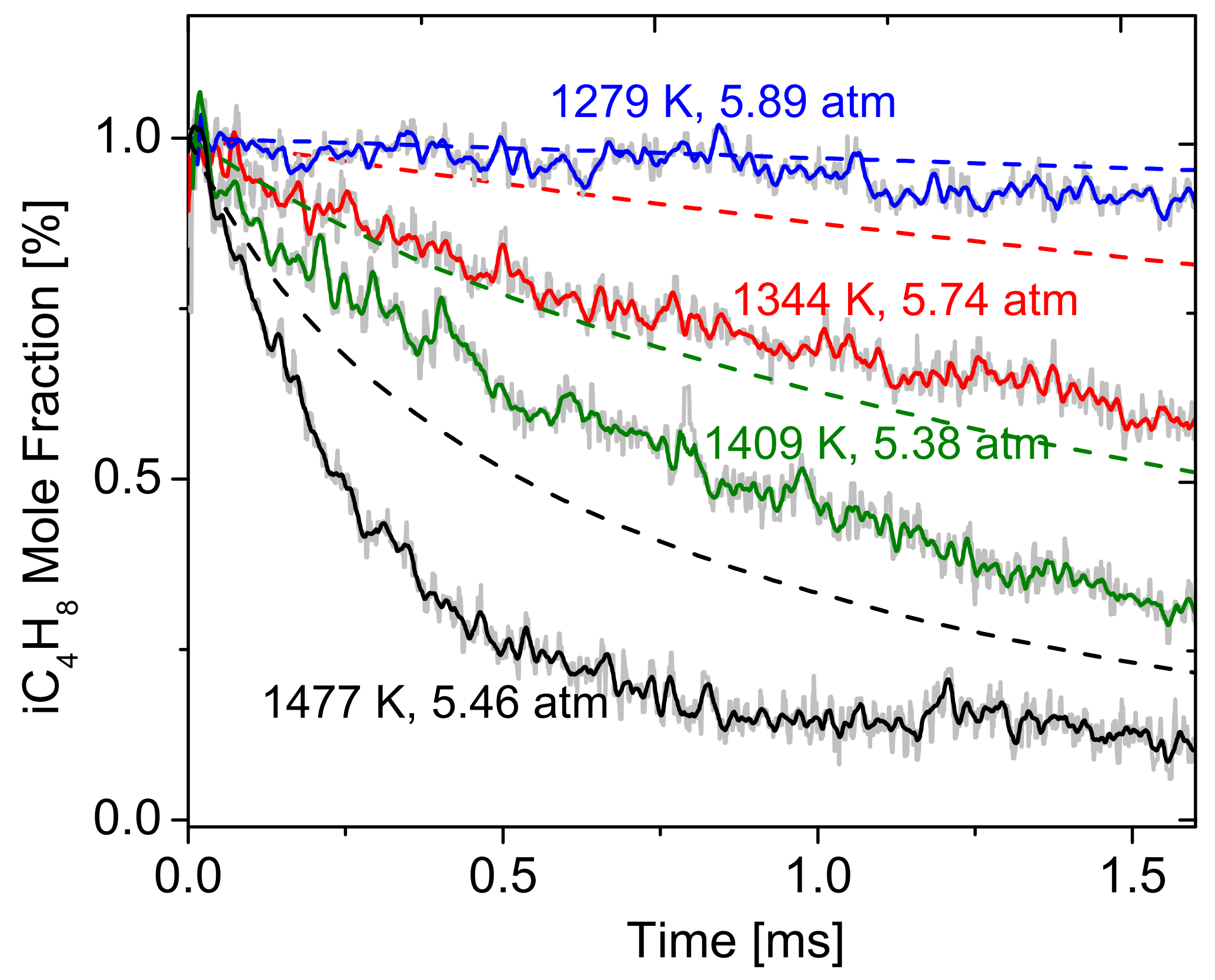




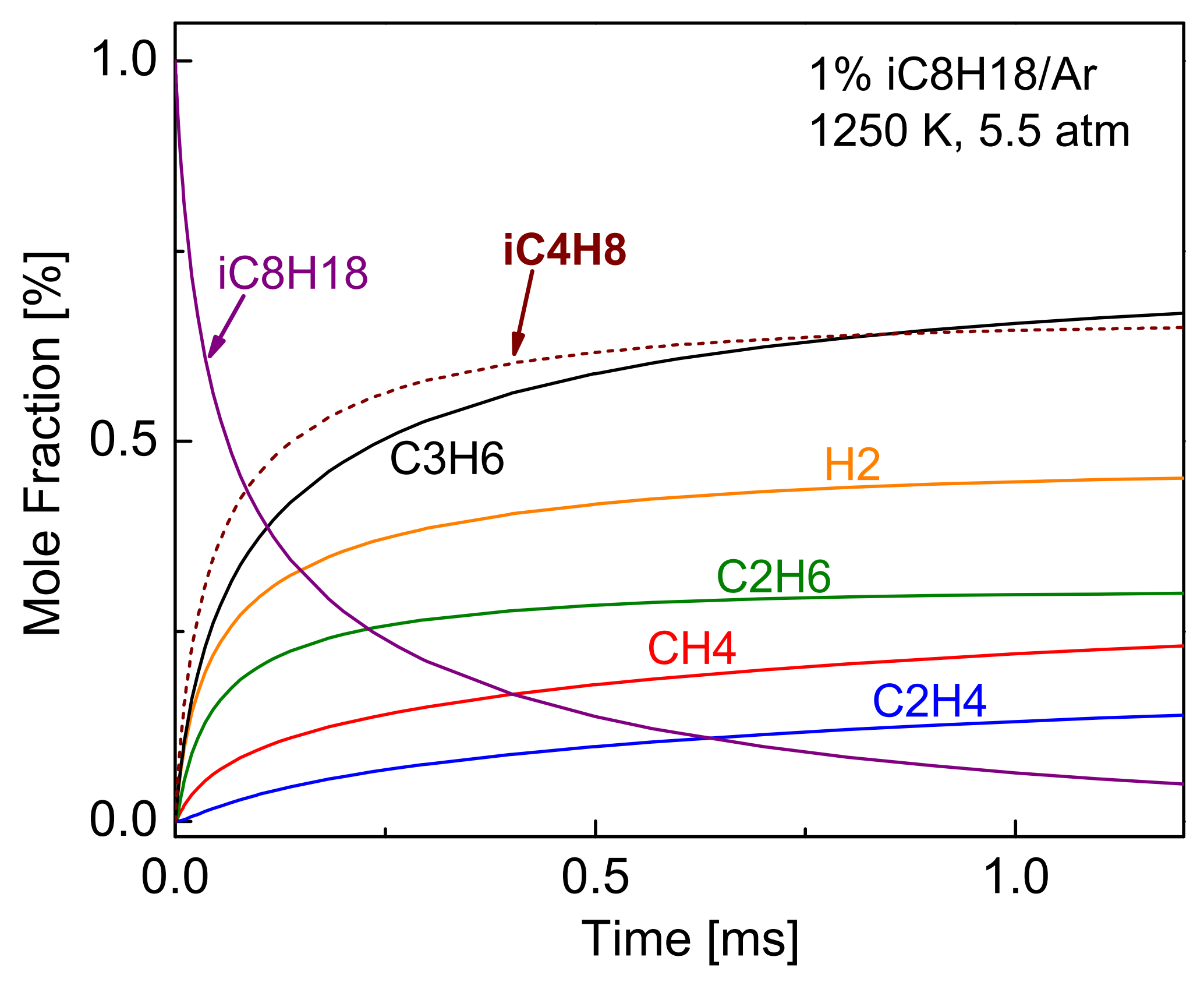

Figure8

\section{$1 \% \mathrm{iC} 8 \mathrm{H} 18 / \mathrm{Ar}$ $1250 \mathrm{~K}, 5.5 \mathrm{~atm}$}

S 


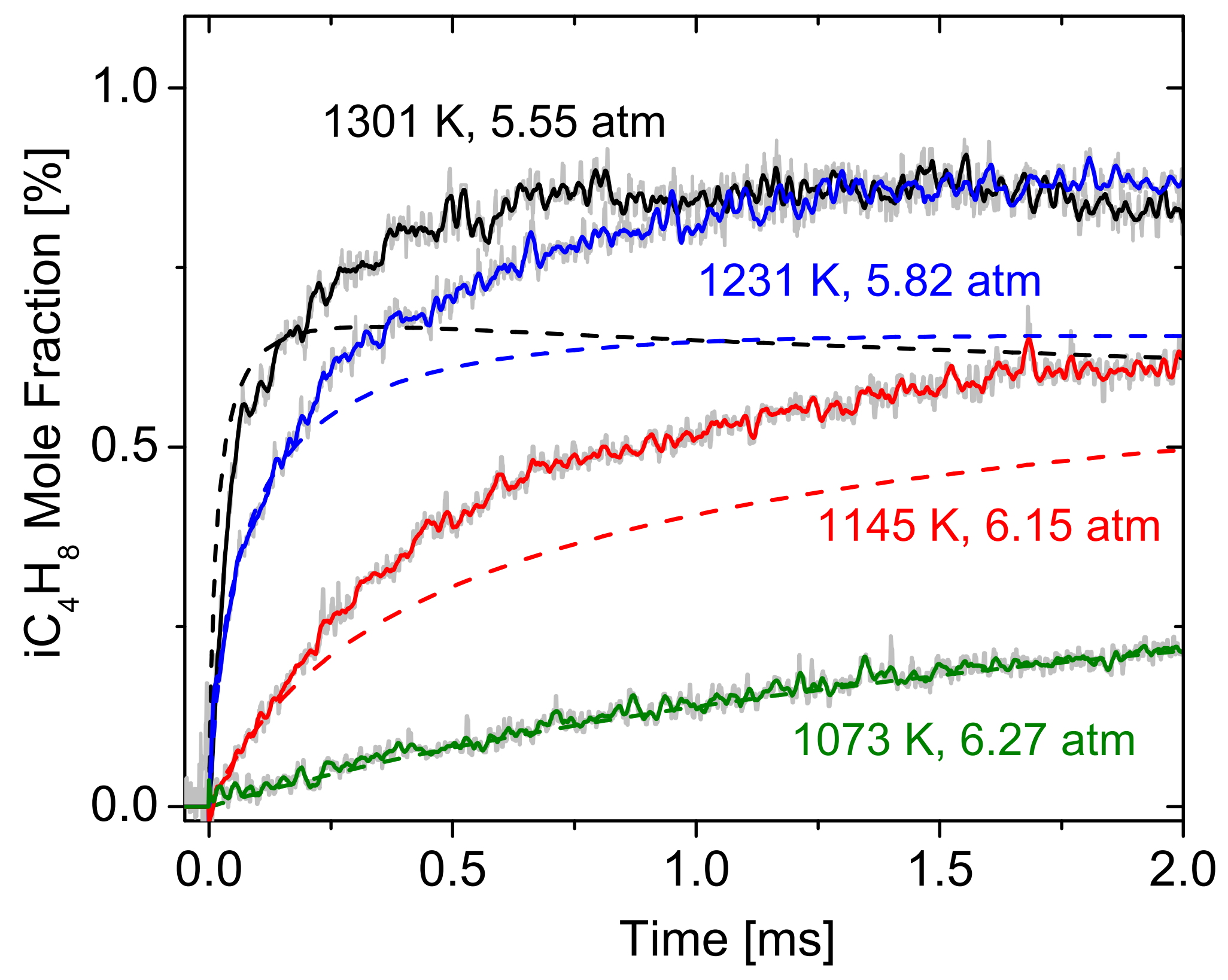

